\title{
O USO DO BLOG COMO ARTEFATO NO PROCESSO ENSINO-APRENDIZAGEM
}

\section{Leila Regina Techio}

leila.1rt@gmail.com

Universidade Federal de Santa Catarina - UFSC

\author{
Ana Elisa Pillon \\ pillon.anaelisa@gmail.com \\ Universidade Federal de Santa Catarina- UFSC \\ Márcio Vieira de Souza \\ marciovieiradesouza@gmail.com \\ Universidade Federal de Santa Catarina- UFSC \\ Richard Perassi \\ richard.perassi@uol.com.br \\ Universidade Federal de Santa Catarina - UFSC \\ Francisco Antonio Pereira Fialho \\ fapfialho@gmail.com \\ Universidade Federal de Santa Catarina - UFSC
}

Resumo: As mudanças na sociedade do conhecimento têm sido ocasionadas pela introdução da tecnologia de forma ubíqua. A educação, assim como as demais áreas - social, política, econômica - vem se moldando e aprimorando-se conforme os avanços tecnológicos, mesmo que haja certa resistência. Frente à esta realidade percebe-se a necessidade de utilizar diferentes artefatos e metodologias inovadoras, tais como a sala de aula invertida, no processo educacional. Sob este enfoque, este artigo tem por objetivo apresentar, através de um estudo de caso, o blog utilizado em uma IES de Santa Catarina. A pesquisa, de caráter descritivo e aplicado, contou com o manuseio de dados quantitativos. A análise dos resultados, por sua vez, apontou que a ferramenta pode ser considerada como um instrumento auxiliar no processo ensino-aprendizagem e, portanto, o uso de recursos midiáticos é indicado também no ambiente educacional.

Palavras-chave: Educação. Weblog. Redes sociais. Artefatos.

\section{Introdução}

A sociedade do conhecimento apresenta diferentes desafios a serem superados e, para que isso ocorra, é imprescindível que haja uma mudança de postura por parte das pessoas, assim como processos flexíveis e metodologias inovadoras. Para acompanhar estas constantes modificações presentes na atualidade torna-se necessário uma adaptação frequente aos novos recursos

\section{2) VIA SEGC}


tecnológicos, bem como adequação aos novos espaços colaborativos e redes cada vez mais conectadas, sejam elas sociais ou econômicas.

Em tempos líquidos, percebe-se que a educação bancária, caracterizada pelo professor assumindo o papel central do processo ensino e aprendizagem, detentor da transmissão do conhecimento e o aluno como coadjuvante da sua aprendizagem, por si só já não traz os resultados eficientes de outrora. Ao comparar as metodologias emergentes aplicáveis na educação atual com as formas tradicionais de ensino, percebe-se que cada vez mais o ensino se apropria de espaços virtuais de ensino, sendo que a introdução das TDIC's (Tecnologias Digitais de Informação e Comunicação) possibilita a imersão no mundo virtual e, com isso, cria-se uma atmosfera de ensino que mescla o virtual com o real.

Outro termo que é frente na academia e apresenta-se em expansão no mundo globalizado é a educação em rede, que representa um contexto caracterizado pela interconexão dos nós em prol da socialização dos conteúdos programáticos. Esta forma de proporcionar o compartilhamento do conhecimento apresenta-se como uma evolução que acompanha as modificações tecnológicas e de comportamento. Como resultado, a educação em rede apresenta-se como a interseção do ensino presencial, à distância e, híbrido (NUNES et al., 2016).

Para ajustar-se a todas essas inovações é preciso repensar a forma de ensinar e aprender, ultrapassando as paredes da sala de aula e adotando gradativamente as TDIC's assim como as diferentes metodologias e ferramentas de aprendizagem (ESPADA, 2012; BAXTO, CARNEIRO, 2019).

Oportuno se torna dizer que a sala de aula invertida apresenta-se como um modelo inovador por mesclar os recursos tecnológicos na educação. O funcionamento desta metodologia segue de forma fluida, sendo que as informações básicas estão disponíveis no espaço virtual, e as atividades são desenvolvidas em sala de aula, onde o professor supervisiona e combina desafios por meio de problemas reais, jogos e projetos. No momento em sala de aula os alunos são estimulados a desenvolver competências como criatividade, comunicação, pensamento crítico e resolução de problemas (MORAN, 2014).

Para McLuhan (1998), todas as mídias são consideradas extensões do homem, pois impactam de alguma forma seu ambiente, já o artefato, como um destes veículos, está relacionado à comunicação, informação e signo da mídia. Neste sentido, reforça o autor que, a cada momento em que observamos um artefato, associamos a ele os valores e juízos, adquiridos no decorrer da nossa história de vida (CARDOSO, 2012).

\section{- VIA GEGC}


Conforme reforça Souza (2019), os produtos mentais compartilhados com um propósito precisam de um meio físico ou mídia para serem comunicados, como exemplo os "memes", que são caracterizados como elementos culturais. Neste contexto, os artefatos constituem-se como meios através dos quais a cultura intangível é propagada e, em face disso, o blog também pode ser considerado um artefato cultural.

Em virtude do que foi mencionado, as redes sociais também são artefatos de mídia e, desta forma, são fundamentais no papel de perpetuar a materialidade da cultura. Estão inseridas no dia a dia das diferentes gerações que, por lazer, trabalho ou necessidade de acompanhar os variados grupos sociais, já não vivem sem a Internet. E, neste contexto, redes sociais, tais como Facebook, WhatsApp, Youtube, Twitter, Linkedin, blog entre outros são consideradas ponto chave na busca por aprimorar as estratégias de aprendizagem (ALMEIDA et al., 2012). Os weblogs ou blogs, em específico, vem sendo incorporados ao processo educacional por tratarem-se de um ambiente familiar à rotina diária dos estudantes como também, por oferecer aos estudantes a capacidade de se tornar coautor de seu próprio aprendizado. De acordo com Gomes et al. (2009), os blogs têm sido usados, principalmente no ensino superior, como "portfólio digital" e, com este enfoque, passa a denominar-se webfólio, blogfólio ou eportifólio.

Em virtude do que foi mencionado, surge a reflexão: Nos moldes educacionais presentes, como o blog pode ser um artefato beneficiador do processo ensino-aprendizagem na educação em rede? Com o intuito de responder à pergunta da pesquisa, este artigo objetiva apresentar um estudo de caso de uma IES que utiliza um blog como espaço colaborativo de ensino dentro da metodologia de sala de aula invertida.

\section{A evolução da educação da tradicional para a educação em rede}

A educação, mesmo que timidamente, vem apresentando mudanças significativas diante da introdução da tecnologia, alterações sobre os valores e costumes que resistem entre diferentes gerações, por meio da interação entre os indivíduos (COSTA, 2009).

Vale lembrar que na educação tradicional o conhecimento flui de forma rígida e hierárquica, e a educação em rede apresenta certa horizontalidade e flexibilidade entre os saberes, conforme Quadro 1. 
Quadro 1 - Características da Educação tradicional X Educação em rede

\begin{tabular}{|c|c|c|}
\hline $\begin{array}{l}\text { Educação } \\
\text { tradicional }\end{array}$ & Descrição & $\begin{array}{l}\text { Educação } \\
\text { em Rede }\end{array}$ \\
\hline $\begin{array}{l}\text { Transmissor do } \\
\text { conhecimento }\end{array}$ & $\begin{array}{l}\text { Papel do } \\
\text { professor }\end{array}$ & $\begin{array}{l}\text { Mediador do } \\
\text { conhecimento }\end{array}$ \\
\hline Passivo & Papel do aluno & Ativo \\
\hline $\begin{array}{c}\text { Aula expositiva } \\
\text { dialogada }\end{array}$ & Metodologia & $\begin{array}{l}\text { Metodologias } \\
\text { ativas }\end{array}$ \\
\hline $\begin{array}{l}\text { Atrapalha, distrai } \\
\text { os estudantes }\end{array}$ & Tecnologia & Ferramenta \\
\hline Rígido & Currículo & Flexível \\
\hline Rígido & Horário & Flexível \\
\hline $\begin{array}{l}\text { Professor para } \\
\text { aluno }\end{array}$ & $\begin{array}{c}\text { Transmissão do } \\
\text { conhecimento }\end{array}$ & $\begin{array}{l}\text { Fluído (professor, } \\
\text { aluno, rede) }\end{array}$ \\
\hline $\begin{array}{l}\text { Exercícios de fixação } \\
\text { tarefa de casa }\end{array}$ & Atividades & Colaborativas \\
\hline Físicas & Redes & Virtuais \\
\hline Individualizado & Conhecimento & $\begin{array}{l}\text { Compartilhado, } \\
\text { flui naturalmente }\end{array}$ \\
\hline
\end{tabular}

Fonte: Os autores (2019)

De acordo com o Quadro 1, pode-se identificar que existem mudanças significativas entre a educação tradicional e a em rede. Essas diferenças são intensificadas pela introdução da tecnologia e mudança de perfil da sociedade como um todo, reforçando que a educação em rede se consolida pelos espaços virtuais conectados presentes na sociedade líquida (BAUMAN, 1999).

\section{Metodologias Ativas na Sala de Aula Invertida}

As competências desenvolvidas por meio da aplicação das metodologias ativas nos cursos de graduação, estimulam a troca de papéis tanto por parte dos professores quanto dos estudantes. Os estudantes precisam adquirir disciplina e engajamento para alcançar um maior aproveitamento na modalidade a distância, ou híbrida. Além disso, no intuito de alcançar a autogestão, a autonomia se torna necessária para o estudante acompanhar o processo de 
aprendizagem da atualidade. O professor, por sua vez, deixa de ser mero transmissor de conhecimento e passa a ser um mediador, facilitando a implementação e prática de metodologias que despertam a autonomia dos discentes no aprender a fazer "fazendo" (CARDOSO et al., 2017).

Em complemento, Souza e Fialho (2018) salientam que a utilização de metodologias ativas envolve diferentes meios definidos pelos autores como "plurifacetados" e "dialógicos". Estes meios podem ser processos didáticos diferenciados, na atualidade apontados como "inovadores", como também podem usar recursos tecnológicos disponíveis nas mídias digitais. Além do exposto, tais autores criaram a Figura 1, em que as mídias digitais são apresentadas como veículo, ou artefatos, e suas interfaces passam a ter papel de canal da mídia, dando suporte ao processo educacional.

Figura 1 - Metodologias Ativas com uso de mídias digitais

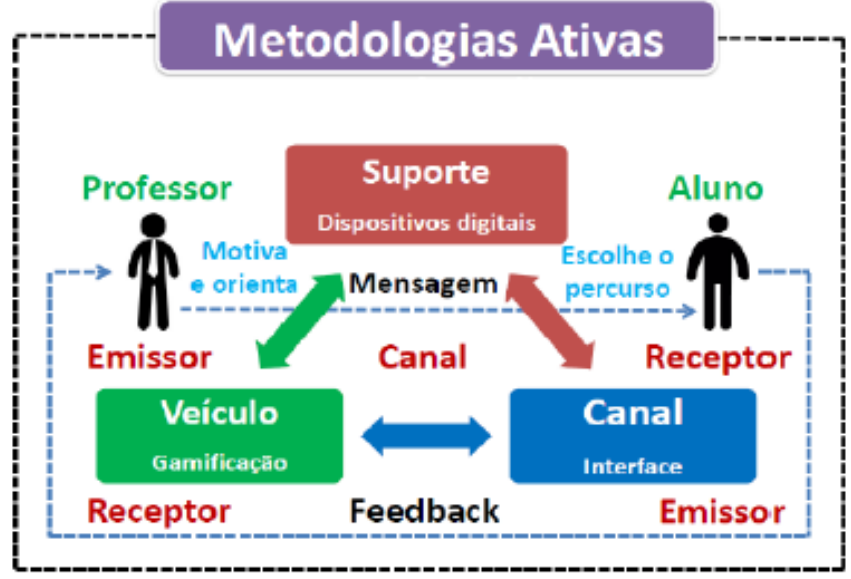

Fonte: Souza e Fialho (2018).

Em análise ao apresentado na Figura 1 percebe-se que a Gamificação está representando um exemplo de veículo, ou seja, uma metodologia ativa que o professor utiliza para motivar e orientar os estudantes. Por sua vez, os dispositivos digitais são considerados suportes no processo comunicativo. O estudante atua como receptor e utiliza a interface como canal para emitir um feedback ao professor. Neste modelo, tanto professor como estudantes tornam-se emissores e receptores, configurando um processo de via dupla.

Cabe, por oportuno, destacar a lição de Amaro e Silva (2017). Para os autores as metodologias ativas têm o papel primordial de despertar o protagonismo dos estudantes, ao passo que eles devem assumir a responsabilidade, de forma criativa e reflexiva, do seu processo educativo. No entanto, ressaltam que o sucesso deste modelo depende da atuação intencional e planejada por parte do professor.

\section{- VIA GEGC}


Em virtude do que foi mencionado, salienta-se que as metodologias vêm sendo cada vez mais empregadas como ações dos professores no modelo de pedagogia emergente. Como exemplo, pode-se destacar o Flipped Classroom, conhecida por sala de aula invertida. Esta ferramenta teve sua origem nos EUA para resolver problemas com os estudantes atletas do ensino médio que precisavam ausentar-se por longos tempos das aulas para os jogos escolares. Seus idealizadores, Jonathan Bergman e Aaron Sams, precisavam encontrar formas diferenciadas de manter os estudantes ativos em seus ensinamentos. Para suprir esta demanda os professores gravaram suas aulas e disponibilizaram na plataforma online junto com outros materiais complementares e exercícios de fixação. Os estudantes precisavam acessar os materiais, conforme seus horários e locais disponíveis e, posteriormente, os estudantes encontravam-se em sala de aula com os professores para a aplicação dos conteúdos disponibilizados nos vídeos e materiais afins. Como o projeto deu certo, decidiram ampliar para os outros estudantes (SCHNEIDER et al., 2013).

Interessante se faz apontar que as inúmeras transformações proporcionadas pela evolução tecnológica e inserção de metodologias como a sala de aula invertida, estimularam adaptações pertinentes à uma educação mais antenada nas possibilidades que essas mutações podem trazer para o ambiente escolar. A sala de aula invertida, como uma destas práticas, proporciona espaços colaborativos de aprendizagem e organização curricular diferenciada, sendo o aluno o protagonista da sua própria aprendizagem. Neste ambiente metodológico, torna-se imprescindível o papel do professor que atua frente ao seu conhecimento dos conteúdos abordados para a identificação do aproveitamento efetivo dos estudantes (SCHNEIDER et al., 2013).

A avaliação, como um dos tópicos vitais para a consecução do processo ensinoaprendizagem não poderia deixar de sofrer algum tipo de atualização também, acompanhando o aprimoramento da educação.

A fim de identificar o aproveitamento dos estudantes na aprendizagem colaborativa, existente em um processo permeado pelos ambientes virtuais, a avaliação entre os pares apresenta-se como uma alternativa viável e, tem sido adotada pela comunidade acadêmica como uma alternativa eficiente no processo contínuo de aprendizagem Os autores ainda reforçam que os estudantes assumem o protagonismo do processo avaliativo e de sua formação colaborativa, aproveitando as facilidades e limitações que o ambiente oferece numa estratégia didático-pedagógica (AMARO; SILVA, 2017).

\section{- VIA GEGC}




\section{O blog e o webfólio como espaços colaborativos na aprendizagem:}

De acordo com McLuhan (1998), as mídias são consideradas como partes estendidas do ser humano, pois no momento em que ocorre o contato entre eles existem mudanças e até mesmo alterações no ambiente ao qual os indivíduos fazem parte, sendo que essas mudanças podem durar ao longo do tempo.

Acompanhando as transformações sociais emergentes e os objetivos envolvidos, os diferentes tipos de pedagogias surgem, e com isso emergem novos espaços e artefatos culturais, diversificando a forma de pensar, agir e de se organizar. A pedagogia cultural contemporânea ocupa diferentes espaços de compartilhamentos como jornais, revistas, sites, redes sociais, programas de TV e outros espaços culturais, entre outros, formando novos artefatos (COSTA; ANDRADE, 2016).

Tendo em vista a possibilidade de utilização de diferentes tecnologias no âmbito educacional, a partir da análise da área de estudo, grau de conhecimento dos estudantes, entre outros fatores, a ferramenta é escolhida e, com vista a alcançar estes objetivos, o blog têm sido amplamente usado. Conforme salientam Silva e Albuquerque (2009), os blogs podem ser usados pelos professores como local de publicação dos materiais e, pelos estudantes para apresentar seus portfólios ou ainda, atuar em diferentes grupos de estudos. Além disso, os blogs podem ser classificados como "diários de bordo" onde são registradas observações e percepções dos participantes (SILVA, 2019), e, principalmente, são apontados como recursos didáticos capazes de potencializar a ação pedagógica docente, facilitando a interação com a informação e coautoria dos estudantes no seu próprio aprendizado (FRAGA et. al., 2011).

A partir de 1966 surgiram os "webfólios" como espaços privilegiados onde ocorrem o registro de processos e produtos de aprendizagem (NEVADO, BASSO, MENEZES, 2004).

Segundo assinalam Grilo e Machado (2005) o webfólio tem como principal característica a apresentação de uma coletânea de trabalhos produzidos pelos estudantes. Neste sentido, esta ferramenta possui a vantagem de oferecer a todos os envolvidos uma visão holística de um determinado tema, e, assim, propiciando um exercício reflexivo, onde o processo de formação passa do individual ao grupal.

\section{Abordagem Metodológica}

A fim de alcançar seus objetivos este estudo iniciou com uma pesquisa bibliográfica em artigos e livros relacionados ao tema. Tendo por base que o estudo busca apresentar as características de determinada população ou fenômeno, neste caso em específico o blog denominado Observatório de Redes Sociais, esta pesquisa é denominada descritiva (GIL,

\section{-2: VIA SEGC}




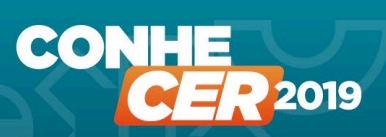

PONTES PARA FUTUROS

2009). Quanto à sua abordagem, por tratar-se de pesquisa com enfoque nos dados coletados por meio do Analytics, em que as informações são utilizadas para posterior classificação e análise, a mesma é classificada como quantitativa.

Além disso, tendo em vista a meta de gerar conhecimentos e, posteriormente aplicar na prática os conceitos abordados, a metodologia empregada quanto à sua natureza é definida como aplicada (GIL, 2009).

\section{Estudo de Caso: Observatório de Redes Sociais}

O objeto de estudo neste artigo é o blog Observatório de redes sociais que é coordenado pelo Laboratório de Mídia e Conhecimento - LABmídia, grupo de pesquisa em Mídia e Conhecimento GPM\&C da Universidade Federal de Santa Catarina - UFSC. Este blog faz parte do pool de recursos utilizados nas disciplinas de Ambientes Virtuais de Aprendizagem - AVA e Redes Sociais e Virtuais, ofertadas de forma optativa nos cursos de graduação de Administração e Economia. Convém ponderar que essas disciplinas são ofertadas no modelo híbrido de ensino, sendo 50\% presencial e 50\% virtual. Por se tratar de uma disciplina moldada de forma ativa, ela passa por constantes adaptações nos recursos, metodologias e avaliações. $\mathrm{O}$ blog Observatório de redes sociais encontra-se disponível para o público desde maio de 2010, porém somente a partir de 2013 passou a ser integrado nas disciplinas.

Para o desenvolvimento do programa das disciplinas são utilizadas aulas teóricas em sala de aula, aulas práticas em laboratório e participação em ambientes virtuais. Nestas disciplinas emprega-se o Moodle, ambiente virtual adotado pela Universidade, o Facebook, e o blog. A respeito, depreende-se os ensinamentos de Souza e Fialho (2018) quanto às metodologias ativas que configuram-se como pedagogias emergentes ou consolidadas. Segundo os autores, dentre as pedagogias consolidadas encontram-se estudo de caso, exercícios em grupo, seminários, portfólio, debates temáticos, entre outros. No que se refere às pedagogias emergentes, são apresentadas gamificação (gamification), ensino híbrido (blended learning), salas virtuais, sala de aula invertida (flipped classroom), MOOC's (Massive Online Open Courses) conhecido como Recursos Educacionais Abertos.

A avaliação das disciplinas ocorre por meio de três etapas, sendo que a primeira N1 refere-se à entrega de um artigo no blog, na N2 a nota será de acordo com a participação nos AVAS (Moodle, blog e grupo do Facebook) e, por fim a nota da N3 será gerada no seminário. Desta forma, a média final (MF) será a média aritmética simples das três avaliações. $M F=(\mathrm{N} 1$ $+\mathrm{N} 2+\mathrm{N} 3) / 3$. 


\section{CON:1:

Para compor a N1 os estudantes precisam escrever um artigo relacionado à disciplina $\mathrm{e}$ postar este artigo no blog. Por se tratar de uma ferramenta alimentada de forma "usual", ou seja, sem impulsionadores de marketing "pago", percebe-se que ocorre um aumento na participação no período de avaliação, mesmo que apresente participações externas ao mesmo. Os alunos das disciplinas são considerados administradores do blog enquanto matriculados nas disciplinas, no entanto ao término do semestre todos os alunos são removidos do blog, para que no próximo semestre sejam adicionados os novos integrantes.

Vale lembrar que nestes moldes de trabalho, a participação dos estudantes marca a transposição da fronteira digital, passando do virtual ao presencial e vice versa, pois os posts são utilizados como materiais de estudo em sala de aula. O professor faz uma seleção dos artigos a serem analisados de forma crítica e os aborda em sala. Neste momento os alunos são engajados a identificar pontos indicadores de qualidade ou não nos materiais, despertando o desenvolvimento da autonomia e capacidade de co-investigação e coautoria, presentes numa inversão de sala de aula, onde os estudantes ajudam a moldar a aula com base no material previamente selecionado e o professor assume o papel de mediador do conhecimento.

Até o semestre 2018/2 o professor realizava a análise dos conteúdos dos posts manualmente, causando morosidade no processo, pois o número de artigos a serem avaliados ficam entre 70 a 80 por semestre. Em 2019/1 foi feita uma adaptação no processo avaliativo, sendo introduzida uma ferramenta com IA (Inteligência Artificial) inserida no Moodle, apresentando alertas relacionados às ações dos estudantes, bem como a utilização da avaliação dos posts que passará a ocorrer por pares. Para Amaro e Silva (2017), na avaliação por pares os estudantes desenvolvem um senso crítico/avaliador e participantes da aprendizagem coletiva, despertando o seu protagonismo no processo educacional.

Por meio da ferramenta do Google Analytics é possível coletar os dados quantitativos deste blog. No Gráfico 1 observa-se as estatísticas de visualizações diárias.

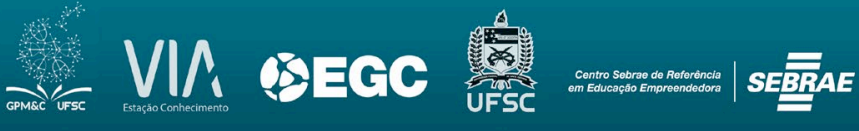


Gráfico 1 - Estatística das visualizações diárias das páginas*

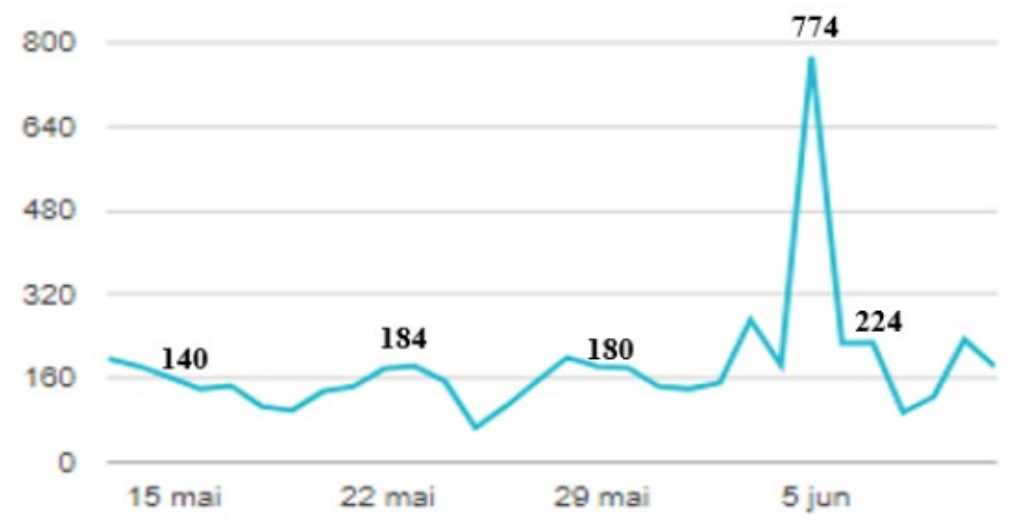

Fonte: Disponível em https://observatorioderedessociais.blogspot.com/

* Dados coletados em 11 junho 2019.

Pode-se observar pelos dados do Gráfico 1, que há um padrão de número de acessos. Destaca-se que ocorre um aumento nas postagens nos períodos de postagens finais de artigos, conforme ocorreu entre os dias 03 e 08 de junho de 2019.

Com os dados coletados no estudo é possível perceber que a metodologia adotada nas disciplinas possibilita o engajamento e um papel ativo dos estudantes no processo de ensinoaprendizagem quando aplicada a sala de aula invertida.

\section{Considerações finais}

O escopo educacional tem sido cada vez mais modificado sob diferentes aspectos, quanto aos métodos de ensino, ambientes onde o processo ensino-aprendizagem em si é efetivado ou, ainda, artefatos participantes deste processo. $\mathrm{O}$ modelo tradicional em que um professor detinha o conhecimento e o transmitia presencialmente aos estudantes foi cada vez mais dando espaço a novos modelos, que hoje inter relacionam diferentes formas de ensinar e aprender, como, por exemplo, o ensino híbrido, que alterna aulas presenciais e a distância.

Com a evolução das tecnologias e a crescente inclusão das TIDC's na rotina diária da sociedade, os ambientes inicialmente utilizados apenas para entretenimento passaram a ser utilizados principalmente com o intuito de aproximar professores e estudantes, que, nas redes sociais, utilizam da mesma linguagem tecnológica.

A exemplo do mencionado, a utilização de um blog como ferramenta na aprendizagem propicia aos estudantes a sensação de ampliação da sala de aula para um espaço virtual, condizente com a sua atualidade. Além disso, neste tipo de atividade os estudantes não são mais apenas receptores passivos do conhecimento, tornando-se coautores da sua aprendizagem.

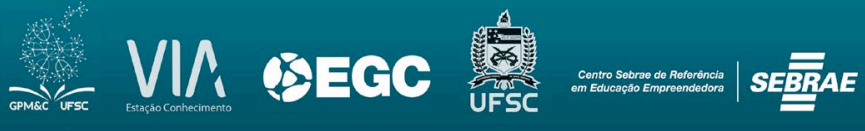


Neste sentido, neste modelo a educação é denominada "em rede" e seus componentes, trocando conhecimento, participam horizontalmente na co-investigação.

Feitas tais considerações pode-se concluir que o blog Observatório de redes sociais vem realizando uma importante função no processo ensino-aprendizagem dos estudantes em análise, comprovando que as redes sociais podem e devem ser utilizadas para suprir a demanda das gerações atuais, cada vez mais conectadas.

Ademais, salienta-se que novos estudos sobre o uso das diferentes redes sociais podem colaborar sobremaneira para a compreensão da evolução de uma sociedade cada vez mais "em rede" e nosso importante papel neste promissor futuro.

\section{Referências}

ALMEIDA, J. M. de; CASTELANO, K. L., SOUZA, C. H. M. de, LUQUETTI, E. C. F.. Uso do Blog na Escola: Recurso Didático ou Objeto De Divulgação? Inter Science Place, [s.1.], v. 1, n. 22, p.174-193, 17 set. 2012. Interscience Place. http://dx.doi.org/10.6020/1679$9844 / 2210$

AMARO, R.; Silva, W. B. da. Avaliação por pares e metodologias ativas na formação de professores. $2^{\circ}$ CIAED - Congresso Internacional ABED de Educação a Distância. 2017. Disponível em: http://www.abed.org.br/congresso2017/trabalhos/pdf/247.pdf. Acesso em 28 jun. 2019.

BAUMAN, Z. Globalização: As Consequências Humanas. Rio de Janeiro: Jorge Zahar Editor, 1999.

BAXTO, W.; CARNEIRO, V. L. Q.. Uso das TIC na educação superior a distância. Educação, [s.1.], v. 42, n. 1, p.35-43, 6 maio 2019. EDIPUCRS. http://dx.doi.org/10.15448/1981-2582.2019.1.28389.

CARDOSO, Rafael. Design para um mundo complexo. São Paulo: Cosac Naify, 2012.

CARDOSO, S. O. S.; OLIVEIRA, E. B. de; CAMARGO, L. S.; JORGETO, F. A.; CANCIAN, W. C.; ZANONI, E.; TERRA, R. R. P.; SILVA, C. A. da; SHIMOHIGASHI, E. R. M. . A Utilização de Metodologias Ativas como Instrumento de Autonomia e Forma de Aprendizagem para o Aluno do Ensino a Distância. Apresentações Trabalhos Científicos, [s.1.], p.1-10, 20 set. 2017. Associação Brasileira de Educação a Distância ABED. http://dx.doi.org/10.17143/ciaed/xxiilciaed.2017.00383.

COSTA, V. B. A Prática Social da Convivência Escolar Entre Estudantes Deficientes Visuais e seus Docentes: o estreito caminho em direção à inclusão. 2009. Dissertação (Mestrado em Educação) - Universidade Federal de São Carlos, São Carlos, 2009.

COSTA, M. V., ANDRADE, P. D. de. Na produtiva confluência entre educação e comunicação, as pedagogias culturais contemporâneas. Perspectiva, [s.1.], v. 33, n. 2, p.843862, 14 mar. 2016. Universidade Federal de Santa Catarina (UFSC).

http://dx.doi.org/10.5007/2175-795x.2015v33n2p843. 
ESPADA, A. B. Redes Sociais e o Impacto na Educação. Janus - III SEDIES 2012, v.9, n.15, p.45-56, 2012. Disponível em:

$<\mathrm{http}: / /$ publicacoes.fatea.br/index.php/janus/article/viewFile/580/410 $>$. Acesso em $17 \mathrm{de}$ jun. 2019.

FRAGA, V. M., SOUZA, P. C. M. de, TRAJANO, S. C. de S., MAFFRA, S. M., SOARES, V. R., NUNES, W. V., OLIVEIRA, A. L. de . Blog como recurso didático pedagógico no ensino de ciências: as tecnologias de ensino na era dos nativos digitais. In: ENCONTRO NACIONAL DE PESQUISA EM EDUCAÇÃO EM CIÊNCIAS, 2011, Campinas. p. 1-11.

GIL, A. C. Métodos e técnicas de pesquisa social. 6. ed. Editora Atlas S/A. 2008.

GOMES, A. P.; RÔÇAS, G.; COELHO, U. C. D.; CAVALHEIRO, P. O.; Gonçalvez; C. A. N. ; Batista, R. S.. Ensino de ciências: dialogando com David Ausubel. Revista Ciências \& Ideias, Teresópolis, v. 1, n. 1, p.23-31. 2009.

GRILO, João Maria e MACHADO, Constança Gomes. "Portfólios" reflexivos na formação inicial de professores de Biologia e Geologia: viagens na terra do eu. In: SÁ-CHAVES, Idália (org.). Os "portfólios" reflexivos (também) trazem gente dentro: reflexões em torno do seu uso na humanização dos processos educativos. Portugal: Porto Editora, 2005, p. 22-49.

MCLUHAN, Marshall. "The Playboy Interview" (pgs. 233-269) in The Essential McLuhan, Ed. Eric McLuhan and Frank Zingrone, NY, Harper Collins, 1998.

MORAN, J. M. Nova personalidade. Brasília: Correio Braziliense. Brasília. Entrevista concedida para Olivia Meireles. Disponível em: http://www2.eca.usp.br/moran/wpcontent/uploads/2014/01/Jos\%C3\%A9-Moran.pdf. Acesso em: 20 jun. 2019.

NEVADO, R. A. de; BASSO, M. V.; MENEZES, C. S. de. Webfólio: uma proposta para avaliação na aprendizagem, conceitos, estudos de casos e suporte computacional. XV SIMPÓSIO BRASILEIRO DE INFORMÁTICA NA EDUCAÇÃO (SBI). 2004. Amazonas. ANAIS. São Paulo: SBIE, 2004. p. 299-308. Disponível em: <https://www.brie.org/pub/index.php/sbie/article/view/331/317>. Acesso em: 01 jun. 2019.

NUNES, L. L. da S. T.; ROSA, L. Q. da; SPANHOL, F. J.; SOUZA, M. V. de. Educação em Rede: Tendências Tecnológicas e Pedagógicas na Sociedade em Rede. EmRede: Revista de Educação a Distância, Porto Alegre/RS, v. 3, n. 2, p.197-212, 2016. ISSN 2359-6082. Disponível em: <https://www.aunirede.org.br/revista/index.php/emrede/article/view/116>. Acesso em: 23 jul. 2019.

SCHNEIDER, E. I., SUHR, I. R. F.; ROLON, V. E. K.; ALMEIDA, C. M. de. Sala de Aula Invertida em EAD: uma proposta de Blended Learning. Revista Intersaberes, Curitiba-PR, v. 8 , n. 16, p.68-81, 1 dez. 2013. ISSN 1809-7286.

SILVA, A. R. L. da (Org.). Experiências significativas para a educação à distância 2. [recurso eletrônico]. Ponta Grossa (PR): Atena Editora, 2019.

SILVA, L.T.; ALBUQUERQUE, M.. Blogs pedagógicos: possibilidades de interação por meio da escrita coletiva de hipertextos cooperativos. Revista Latinoamericana de

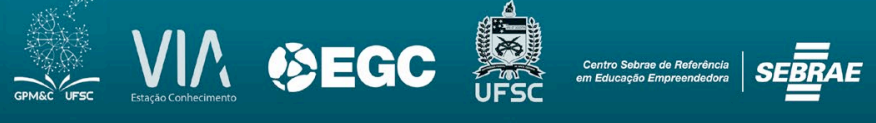


Tecnología Educativa - RELATEC, 8 (2), 91-108, 2009. Disponível em:

$<$ http://campusvirtual.unex.es/cala/editio/>. Acesso em 28 mai. 2019.

SOUZA, R. P. L. de. Mídia do Conhecimento: Ideias sobre Mediação e Autonomia. 1. ed. CCE/UFSC: Florianópolis/SC, 2019.

SOUZA, E. de; FIALHO, F. A. P.. Teaching skills for the use of active methodologies supported with digital media. International Congress of Knowledge and Innovation Ciki, [S.1.], v. 1, n. 1, sep. 2018. 